Artigo Científico

\title{
Micropropagação de Ananas bracteatus (Shultz) cv. striatus Hort.
}

\author{
TALÍA DA COSTA ${ }^{1}$ e GILMAR ROBERTO ZAFFARI ${ }^{2}$
}

\section{RESUMO}

O Estado de Santa Catarina, apesar de conhecido pela forte economia industrial e agrícola, conta ainda com um mercado interno a ser abastecido. A horticultura ornamental possibilita a geração de empregos, de fixação do homem no campo e de fortalecimento de pequenos e médios produtores, podendo também ser utilizada em escala comercial. Com este objetivo, obteve-se um protocolo para a micropropagação de Ananas bracteatus (Shultz) cv. striatus Hort. Foram utilizadas gemas laterais do pseudocaule, como fonte de explantes. A assepsia dos explantes foi feita com etanol 70\% (v/v), durante cinco segundos, seguida de imersão em NaOCl 1\% (v/ v), durante 15 minutos. Os explantes foram inoculados em meio MS líquido suplementado de 2,16 mM de ANA e 4,0 mM de BAP, durante 45 dias de cultivo. Meio MS líquido, suplementado com ANA (2,16 mM) e BAP $(4,0 \mathrm{mM})$, resultou num melhor desenvolvimento dos explantes na fase de estabelecimento quando comparado com os meios sólidos. A presença isolada de BAP, nas fases de multiplicação (I, II e III), não foi eficiente para aumentar a taxa de multiplicação. A combinação de ANA $(2,16 \mathrm{mM})$ e BAP $(8,89 \mathrm{mM})$ foi necessária para se obter um maior número de brotos por explantes. A passagem dos explantes em mais de um cultivo, nas fases de multiplicação e de crescimento, teve como efeito o aparecimento de variantes somaclonais, originando plântulas verdes e albinas.

Palavras-chave: abacaxizeiro ornamental, propagação in vitro, variegação.

\begin{abstract}
The State of Santa Catarina is known for the intense agricultural and industrial economy, there is yet, an intern market to be provided. The ornamental horticulture makes it possible the employment, the establishment and the strengthening of small and medium growers, the ornamental micropropagation can be used in large scale. With these objectives, we studied the Ananas bracteatus (Shultz) cv. striatus Hort., establishing an in vitro culture protocol to the specie. Lateral buds were utilized as explants source. The asseptical treatment was realized in ethanol 70\% (v/v) during 5 seconds and $\mathrm{NaOCl} 1 \%(\mathrm{v} / \mathrm{v})$ during 15 minutes. The explants were inoculated in medium MS liquid with ANA $(2.16 \mathrm{mM})$ and BAP $(4.0 \mathrm{mM})$, during 45 days of cultivation. Liquid medium treatment with ANA $(2.16 \mathrm{mM})$ e BAP $(4.0 \mathrm{mM})$ resulted in the best explants development on the establishment phase than with solid medium. The isolated presence of BAP, on the proliferation phase, not showed efficiency in promotes a multiplication tax increase. It was necessary a combination between the grown regulator ANA $(2.16 \mathrm{mM})$ and BAP $(8.89 \mathrm{mM})$ concentration utilities to obtain a higher number of buds to explants. The subcultures, in the multiplication phase and the grown phase, resulted on the somaclonal appear green and albino plantlets.
\end{abstract}

Keywords: ornamental pineapple, in vitro propagation, variegation.

\section{INTRODUÇÃO}

O Estado de Santa Catarina é conhecido pela forte economia industrial e agrícola. A horticultura ornamental também se insere neste contexto como geradora de rendas ao produtor. Com a criação da Associação de Produtores de Plantas Ornamentais do Estado de Santa Catarina (APROESC) e do Mercado de Flores e Plantas Ornamentais de Santa Catarina (Mercaflor), houve um aumento na produção de flores e plantas ornamentais e, conseqüentemente, oferta no mercado (BUDAG \& SILVA, 2000).

Muitos produtores têm encontrado dificuldade na propagação de algumas espécies de plantas ornamentais aplicando métodos convencionais, devido ao longo período de tempo para a obtenção da muda, além da baixa qualidade genética e fitossanitária, bem como desuniformidade no tamanho.

Técnicas de cultura de tecidos de plantas são ferramentas para a propagação de espécies ornamentais, mas a multiplicação in vitro é a que oferece várias vantagens sobre os métodos convencionais, pois, pode-se conseguir rapidamente mudas em larga escala, num período de tempo e espaço físico reduzidos (LAUZER et al., 1992), e também produzir plântulas isentas de patógenos, bem como proporcionar a melhora qualitativa das mudas com a obtenção de lotes uniformes (TORRES et al., 1998).

\footnotetext{
${ }^{1}$ Bióloga, Mestranda em Biologia Vegetal - Laboratório de Fisiologia Vegetal, Departamento de Botânica, Universidade Federal de Santa Catarina, Florianópolis, Santa Catarina

${ }^{2}$ Eng. Agrônomo, Dr., UNIVALI e Estação Experimental de Itajaí (Epagri), Caixa Postal 277, CEP 88301-970, Itajaí, Santa Catarina.
} 
Ananas bracteatus (Shultz) cv. striatus Hort, conhecida popularmente como ananás ornamental, é uma planta herbácea, perene, originária do Brasil, podendo medir até $60 \mathrm{~cm}$ de altura, com folhagem variegada, cujo o centro da folha é verde com listras amarelas nas bordas (LORENZI \& SOUZA, 1999). Pode ser utilizada como cerca viva, para impedir o trânsito de pessoas ou animais no jardim, pois há espinhos em suas folhas. A multiplicação vegetativa é dominante sobre a propagação por sementes. Entretanto, há uma deficiência de trabalhos de propagação vegetativa in vitro dessa espécie, o que estimulou o seu estudo e até a obtenção de um protocolo.

\section{MATERIAL E MÉTODOS}

O estudo foi conduzido no Laboratório de Biotecnologia, na Empresa de Pesquisa Agropecuária e Difusão de Tecnologia de Santa Catarina S.A., da Estação Experimental de Itajaí. As plantas matrizes do abacaxi ornamental permaneceram em casa de vegetação sob temperatura média de $18,02^{\circ} \mathrm{C}$ e umidade relativa do ar de $83,14 \%$.

Os materiais utilizados como fonte de explante foram gemas laterais da porção média do pseudocaule, retiradas em forma de cubos, com tamanho aproximado de $0,5 \mathrm{~cm}^{3}$. Após o seccionamento, o material foi imerso imediatamente em frascos contendo água destilada e esterilizada. No laboratório, os explantes foram submetidos às soluções de etanol 70\% (v/v), durante cinco segundos, e de hipoclorito de sódio $1 \%(\mathrm{v} / \mathrm{v})$, durante 15 minutos. Cada explante foi inoculado em meio de cultura líquido (MURASHIGE \& SKOOG, 1962) suplementado com 2,16 mM de ANA (ácido a-naftaleno acético) e 4,0 mM de BAP (6-benzilaminopurina), devido à escassez de material vegetal, no sistema ponte de papel, frasco de vidro, com capacidade de $100 \mathrm{~mL}$, contendo $20 \mathrm{~mL}$ de meio líquido, foi vedado com tampa plástica despigmentada. Após 45 dias de incubação, as percentagens de explantes mortos, sobreviventes e contaminados foram avaliadas, e os explantes estabelecidos assepticamente foram utilizados nas etapas seguintes.

Após a assepsia, foram testados quatro meios de cultura para a fase de estabelecimento, com presença e ausência de reguladores de crescimento e de agente geleificante ágar-ágar 0,7\% (p/v): T1: MS líquido; T2: MS líquido + 2,16 mM ANA + 4,0 mM BAP; T3: MS sólido; T4: MS sólido + 2,16 mM ANA + 4,0 mM BAP. As variáveis avaliadas foram: tamanho do explante, coloração das gemas, porcentagem de gemas vivas e contaminadas, formação de calos e de raízes, e número de folhas. O delineamento experimental foi completamente casualizado, com cinco repetições por tratamento, tendo um explante por parcela. Os dados foram submetidos à análise de variância e a comparação das médias foi realizada pelo teste de Tukey à significância de $5 \%$.

A fase de multiplicação foi subdividida em três, sendo que para todas as fases (I, II e III) os tratamentos foram idênticos (T1: MS + 4,0 mM BAP; T2: MS + 1,08 mM ANA + 8,0 mM BAP; T3: $\mathrm{MS}+2,16 \mathrm{mM}$ ANA + 4,0 mM BAP; T4: $\mathrm{MS}+2,16 \mathrm{mM}$ ANA + 8,89 mM BAP e T5: MS + 4,32 mM ANA + 8,0 mM BAP). As variáveis avaliadas foram percentagem de contaminação, número médio de brotos por explantes, altura média dos brotos e presença de variantes somaclonais.

Apenas após a fase de multiplicação I, os explantes foram transferidos para um meio único, compostos de meio líquido MS (fase de crescimento), onde permaneceram 45 dias, sendo transferidos para os tratamentos da fase de multiplicação II e, 45 dias após, para a fase de multiplicação III.

O delineamento experimental foi completamente casualizado, com 3 repetições para a fase de multiplicação I, 24 repetições para a fase de multiplicação II e 42 repetições para a fase de multiplicação III, tendo um explante por parcela. Os dados foram submetidos à análise de variância e teste de comparação de médias Tukey, num nível de significância de 5\%.

As culturas permaneceram em sala de crescimento à temperatura de $25^{\circ} \mathrm{C} \pm 2^{\circ} \mathrm{C}$, umidade relativa do ar de aproximadamente $60 \%$, luz branca de intensidade 50 mmol.m $\mathrm{m}^{-2} \cdot \mathrm{s}^{-1}$ e 16 horas de luz.

\section{RESULTADOS E DISCUSSÃO}

O efeito dos meios de cultura, na fase de estabelecimento, é mostrado na tabela 1. Somente o tamanho médio dos explantes foi significativo (5\%), sendo o tratamento 2 o que apresentou maior altura média dos explantes. Isto ocorreu, provavelmente, devido à interação de dois fatores: primeiro, a presença dos reguladores de crescimento no meio de cultura que, de acordo com ARTECA (1995), tem como objetivo principal suprir as possíveis deficiências endógenas nos explantes, quando estes são isolados das plantas matrizes; o outro, determinante, foi o emprego de meio líquido, considerando que neste há maior homogeneidade, o que permite maior velocidade de difusão e de absorção dos nutrientes para os tecidos. (Figura 1).

O controle da rizogênese pode ser influenciado por reguladores de crescimento, sendo que as auxinas aumentam consideravelmente a formação de primórdios radiculares (ASSIS \& TEIXEIRA, 1998). Quanto à percentagem de explantes com raízes, apenas os tratamentos sem reguladores de crescimento (T1 e T3) apresentaram plântulas com raízes. Este resultado sugere que, para Ananas bracteatus (Shultz) cv. striatus Hort, a presença de uma auxina associada à citocinina inibe a formação de primórdios radiculares. Não houve formação de calo, e as gemas desenvolvidas alcançaram padrão variegado em todos os tratamentos da fase de estabelecimento da cultura.

Os resultados das fases de multiplicação são descritos na tabela 2. Apenas no número médio de brotos/ explantes houve diferenças significativas, $(5 \%)$ nas três fases: tendo o tratamento I a menor média obtida, com 1,33, 0,76 e 2,38 brotos/explantes nas fases de multiplicação I, II e III, respectivamente (Figura 2). Esses resultados evidenciam que somente a presença de citocinina no meio de cultura não foi suficiente para induzir respostas morfogenéticas. Porém, na fase de multiplicação III, o tratamento 4 apresentou maior taxa de multiplicação em relação aos demais tratamentos, com 4,71 brotos/explantes. A transferência dos explantes, após a fase de multiplicação I, 
Tabela 1. Variáveis avaliadas em explantes de Ananas bracteatus (Shultz) cv. striatus Hort. inoculados em meios MS (1962), líquido e sólido, suplementados ou não com ANA e BAP após 45 dias de cultivo, na fase de estabelecimento.

\begin{tabular}{|c|c|c|c|c|c|c|c|}
\hline \multicolumn{3}{|c|}{ Tratamentos } & \multirow{2}{*}{$\begin{array}{l}\text { Tamanho médio } \\
\text { dos explantes } \\
(\mathrm{mm})\end{array}$} & \multirow{2}{*}{$\begin{array}{c}\text { Gemas } \\
\text { vivas } \\
(\%)\end{array}$} & \multirow{2}{*}{$\begin{array}{c}\text { Contaminação } \\
(\%)\end{array}$} & \multirow{2}{*}{$\begin{array}{c}\text { Explantes } \\
\text { com raízes } \\
(\%)\end{array}$} & \multirow{2}{*}{$\begin{array}{c}\text { Folhas } \\
\left(\mathbf{n}^{0}\right)\end{array}$} \\
\hline & $\underset{(\mu)}{\text { ANA }}$ & BAP & & & & & \\
\hline T1- líquido & - & - & $9,33 \pm 1,53 a b$ & 80 & 20 & 40 & $5,33 \pm 0,58 \mathrm{a}$ \\
\hline T2- líquido & 2,16 & 4,0 & $9,67 \pm 0,58$ a & 80 & 20 & 0 & $5,67 \pm 1,53 \mathrm{a}$ \\
\hline T3- sólido & - & - & $8,67 \pm 1,15 \mathrm{ab}$ & 80 & 20 & 40 & $3,67 \pm 0,58 \mathrm{a}$ \\
\hline T4- sólido & 2,16 & 4,0 & $5,67 \pm 1,15 b$ & 60 & 0 & 0 & $3,33 \pm 2,31 \mathrm{a}$ \\
\hline
\end{tabular}

Médias \pm desvio padrão de $\mathrm{N}=5$.

Médias seguidas pelas mesmas letras não diferem entre si à significância de 5\% pelo teste de Tukey.

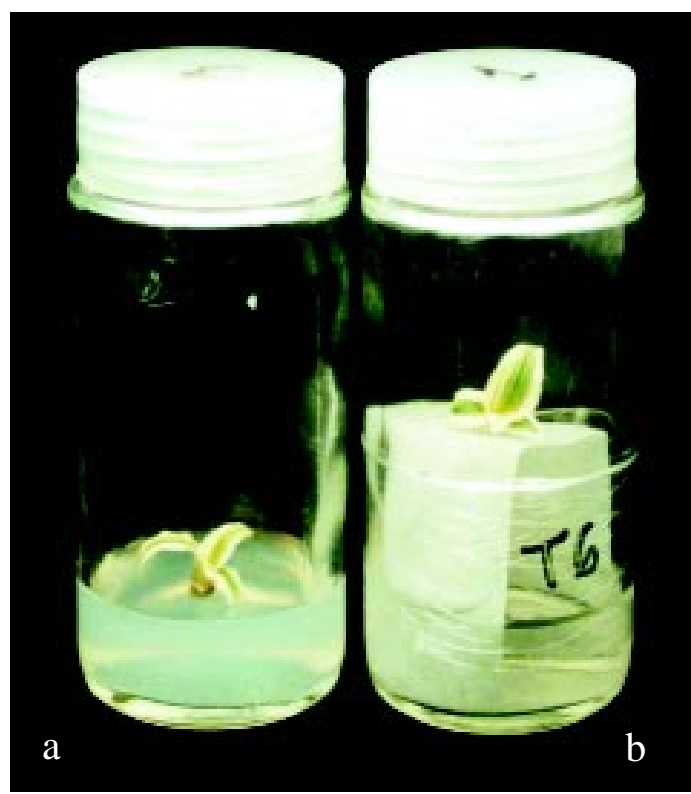

Figura 1. Fases da micropropagação, a partir de gemas de Ananas bracteatus (Shultz) cv. striatus Hort. 1. explantes inoculados em meio MS (1962), sólido (a) e líquido (b), após 45 dias.

para o meio MS líquido resultou numa baixa taxa de multiplicação dos explantes quando estes foram inoculados na fase de multiplicação II. Segundo GRATTAPAGLIA \& MACHADO (1998), o explante necessita se restabelecer do estresse pós-repicagem e se desenvolver lentamente. Entretanto, o aumento na taxa de multiplicação, na fase de multiplicação III, foi devido ao efeito residual do regulador de crescimento BAP, uma vez que o efeito das citocininas não se restringe a uma subcultura e podem ser constatados resíduos na subcultura posterior (TORRES et al., 1998).

$\mathrm{Na}$ fase de crescimento houve um aumento no número de brotos em $85 \%$, em função do provável efeito residual do BAP. Nessa etapa observou-se variação somaclonal, com plântulas albinas $(52,56 \%)$ e plântulas verdes $(20,51 \%)$. O aparecimento de plântulas variegadas pode ser explicado devido à presença de células heteroplastídicas (MARCOTRIGIANO, 1997), uma vez que durante a divisão celular os cloroplastos também são divididos.

\section{CONCLUSÕES}

1. Para a fase de estabelecimento, meio líquido MS suplementado com 2,16 mM de ANA e 4,0 mM de BAP apresenta melhor resposta em relação a altura de brotos.

2. A combinação de citocinina e auxina promove maior taxa de multiplicação dos explantes.

3. A permanência dos explantes em meio MS na fase de crescimento, bem como por mais de um subcultivo nos tratamentos, promove diferentes padrões morfogenéticos e o desenvolvimento de variação somaclonal, com o aparecimento de plântulas albinas e verdes. 
Tabela 2. Variáveis avaliadas em explantes de Ananas bracteatus (Shultz) cv. striatus Hort. inoculados em meio MS (1962), com diferentes concentrações de ANA e BAP após 45 dias de cultivo, nas fases de multiplicação I, II e III.

\begin{tabular}{|c|c|c|c|c|}
\hline & $\begin{array}{l}\text { atamen } \\
\text { ANA } \\
(\mu)\end{array}$ & OS & $\begin{array}{l}\text { Altura média } \\
\text { dos brotos } \\
\text { (cm) }\end{array}$ & $\begin{array}{c}\mathbf{N}^{\mathbf{o}} \text { médio de brotos/ } \\
\text { explante }\end{array}$ \\
\hline \multicolumn{5}{|c|}{ Fase de Multiplicação I } \\
\hline T1 & - & 4,0 & $1,38 \pm 0,63 a$ & $1,33 \pm 0,58 b$ \\
\hline $\mathbf{T} 2$ & 1,08 & 8,0 & $0,93 \pm 0,43 \mathrm{a}$ & $7,33 \pm 1,15 \mathrm{a}$ \\
\hline T3 & 2,16 & 4,0 & $1,32 \pm 0,50 \mathrm{a}$ & $7,33 \pm 1,53 \mathrm{a}$ \\
\hline T4 & 2,16 & 8,89 & $0,76 \pm 0,33 \mathrm{a}$ & $6,33 \pm 1,15 \mathrm{a}$ \\
\hline T5 & 4,32 & 8,0 & $0,82 \pm 0,38 \mathrm{a}$ & $5,66 \pm 1,53 \mathrm{a}$ \\
\hline \multicolumn{5}{|c|}{ Fase de Multiplicação II } \\
\hline T1 & - & 4,0 & $0,68 \pm 0,20 \mathrm{a}$ & $0,76 \pm 0,44 b$ \\
\hline $\mathbf{T} 2$ & 1,08 & 8,0 & $0,75 \pm 0,33 \mathrm{a}$ & $2,19 \pm 0,40 \mathrm{a}$ \\
\hline T3 & 2,16 & 4,0 & $0,69 \pm 0,29 a$ & $1,95 \pm 0,50 \mathrm{a}$ \\
\hline T4 & 2,16 & 8,89 & $0,78 \pm 0,28 \mathrm{a}$ & $2,38 \pm 0,50 \mathrm{a}$ \\
\hline T5 & 4,32 & 8,0 & $0,62 \pm 0,29 a$ & $2,05 \pm 0,59 \mathrm{a}$ \\
\hline \multicolumn{5}{|c|}{ Fase de Multiplicação III } \\
\hline T1 & - & 4,0 & $1,08 \pm 0,47 \mathrm{a}$ & $2,83 \pm 0,54 \quad c$ \\
\hline $\mathbf{T 2}$ & 1,08 & 8,0 & $0,99 \pm 0,47 \mathrm{a}$ & $3,81 \pm 0,40 \quad b$ \\
\hline $\mathbf{T 3}$ & 2,16 & 4,0 & $1,14 \pm 0,58 \mathrm{a}$ & $3,76 \pm 0,43 \quad b$ \\
\hline T4 & 2,16 & 8,89 & $0,96 \pm 0,51 \mathrm{a}$ & $4,71 \pm 0,46 \mathrm{a}$ \\
\hline T5 & 4,32 & 8,0 & $0,94 \pm 0,48 \mathrm{a}$ & $3,79 \pm 0,42 \quad b$ \\
\hline
\end{tabular}

Médias seguidas pelas mesmas letras não diferem entre si à significância de 5\% pelo teste de Tukey. (médias desvio padrão de N=3 na fase de multiplicação I; $\mathrm{N}=24$ na a fase de multiplicação II e $\mathrm{N}=42$ na a fase de multiplicação III).

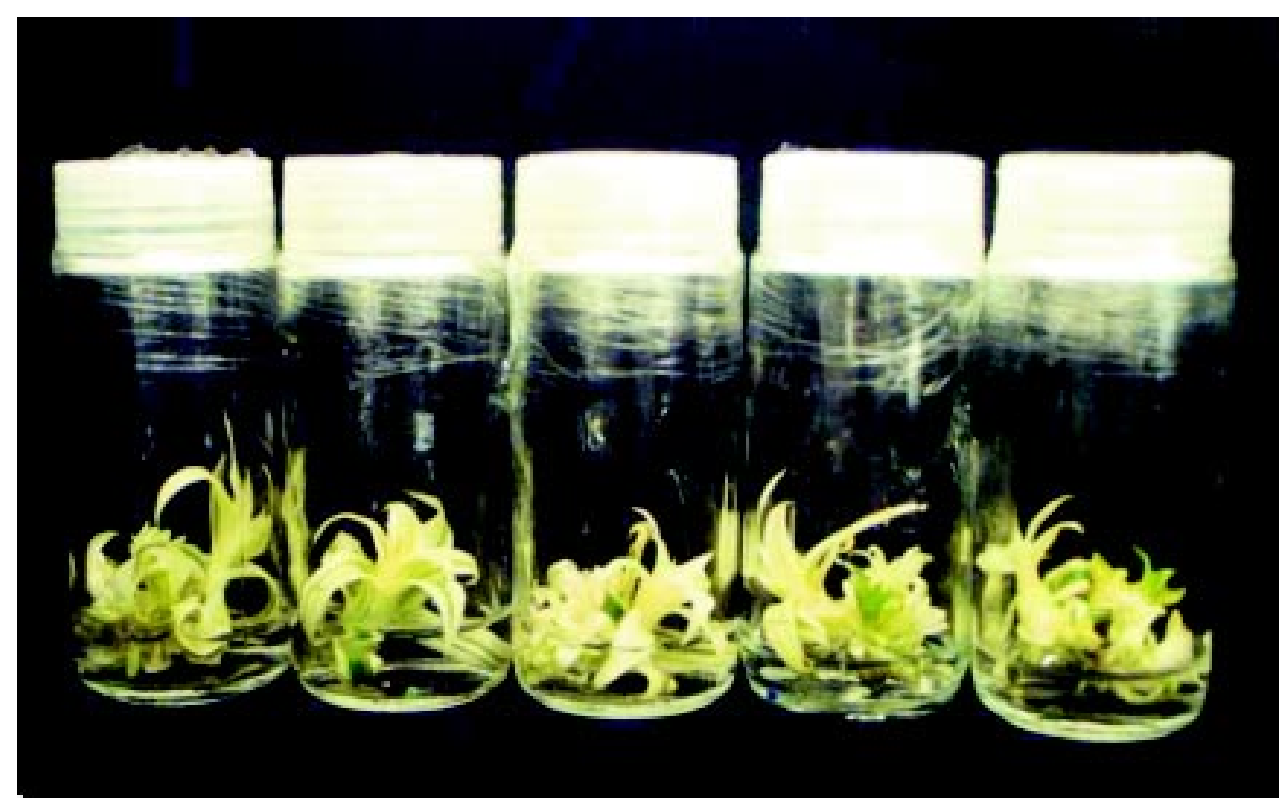

Figura 2. Taxa de multiplicação do explantes inoculados na fase de multiplicação, após 45 dias. 


\section{REFERÊNCIASBIBLIOGRÁFICAS}

ARTECA, R. N. Plant growth substances: principles and applications. Chapman \& Hall, 1995. $331 \mathrm{p}$.

ASSIS, T. F.; TEIXEIRA, S. L.; Enraizamento de plantas lenhosas. In: TORRES, A. C.; CALDAS, L. S.; BUSO, J.A. Cultura de Tecidos e Transformação Genética de Plantas. Brasília: EMBRAPA-SPI/EMBRAPA-CNPH, 1998. v.1, p 261-296.

BUDAG P.R.; SILVA, T.P. da. Cadeias produtivas do Estado de Santa Catarina: Flores e plantas ornamentais. Florianópolis : Epagri, 2000. 51p. (Circular, 106).

GRATTAPAGLIA， D.; MACHADO， M. A. Micropropagação. In: TORRES, A. C.; CALDAS, L. S.; BUSO, J. A. Cultura de Tecidos e Transformação Genética de Plantas. Brasília:EMBRAPA-SPI/EMBRAPA-CNPH, 1998. v.1.p. $183-242$
LAUZER, D.,LAUBLIN, G, VINCENT, G \& CAPPADO-CIA, M. In vitro propagation and cytology of wild yams, Dioscorea abyssinica Hock. and D. mangenotiana Miège. Plant Cell, Tissue and Organ Culture, Kluwer Academic Publishers, v. 28, p. 215-223, 1992.

LORENZI, H.; SOUZA, H. M. de. Plantas Ornamentais no Brasil: Arbustivas, herbáceas e trepadeiras. 2. ed. Nova Odessa, SP : Instituto Plantarum, 1999.

MARCOTRIGIANO, M. Chimeras and Variegation: Patterns of Deceit. HortScience, Washigton, v. 32(5), p. 773-784, 1997.

MURASHIGE, T.; SKOOG, F. A revised medium for rapid growth and bioassays with tobacco tissue cultures. Physiology Plantarum, Copenhagen, v.15, p. 473-497, 1962.

TORRES, A. C.; CALDAS, L. S.; BUSO, J. A. Cultura de Tecidos e Transformação Genética de Plantas. Brasília : EMBRAPA-SPI/EMBRAPA-CNPH. 1998. 2v. 